\title{
Factors affecting configuration plans in product development
}

\author{
Arik Sadeh ${ }^{1,2^{*}}$, Shlomi Gecht ${ }^{1}$ and Cristina Feniser $^{3}$ \\ ${ }^{1}$ HIT Holon Institute of Technology, 52 Golomb St. Holon, 58102, Israel \\ ${ }^{2}$ Visiting Research Associate, Hebrew University of Jerusalem, Rehovot, Israel \\ ${ }^{3}$ Technical University of Cluj-Napoca, Romania
}

\begin{abstract}
Configuration Management( $\mathrm{CM}$ )is an engineering methodology through which it is possible to manage and control all the stages that the product undergoes throughout its life cycle. The applied methodology is relevant to many different engineering disciplines and various products. CM is part of system engineering and it includes many management aspects. This study deals with factors that make up the CM configuration management methodology of all its components. The background and motivation for conducting this research was raised from inspection of outcomes from many development processes of new products, or improvement and changes in design of existing products, in hi-tech organizations in Israel. It was found that in some organizations the issue of configuration management is often not large or not large enough, and accordingly, too little resources are allocated to the subject. The study refers to the configuration management schema according to CMII (Configuration Management version 2). The study examines the level of configuration management with respect to the effects of the following variables and their level in the organization: (i) Requirements Management), (ii) Change Management, (iii) Release Management), (iv) Data Management), (v) Report Management, (vi) Document Management, and (vii) Software Tools Management. The study includes a comprehensive survey of 104 system engineers, managers and project managers related to the field of configuration management processes. The results of the study indicate the relative importance of each factor involved in configuration management. They are very useful for organizations whose main focus is research and development and new product development
\end{abstract}

\section{Introduction}

The professional field and the content world of this work are in the field of Systems Engineering. It incorporates the engineering aspect of the definition of requirements, product design, definition of stakeholders, and documentation of information, definition of specifications and interfaces and solution of technical problems. In the managerial aspect, systems engineering combines many professions in order to produce a structured

*Corresponding author: sadeh@hit.ac.il 
development process that will advance from the concept stage and initiation to the production stage, and from there to the life cycle of the product until the end of its life and its removal.

Configuration Management is an engineering methodology through which you can manage and monitor all the steps it goes through the product throughout its life cycle, since the beginning of the design development through compliance to specifications and requirements. It includes the design of a prototype model, serial production (Mass Production), support of the production process up to the stage of disposal and end of the product life cycle. The applied methodology is relevant to many different engineering disciplines.

Although there are fine methodologies in hi-tech industries, mangers reported about such problems:

-There are situations where employees are working with specifications that are not released;

-There are situations where you work with outdated drawings;

-Produce products that are unsuitable for work;

-Cannot start production process;

-Logistical problems;

-Items cannot be approved by the customer;

-There are situations where items do not meet environmental conditions;

-Obsolete and End User problems.

These gives rise to investigate the actual role of configuration management and how it is perceived by professional system engineers and project managers.

\subsection{Background and literature review}

In this section some main factors that affect and are involved in configuration management and its exercise in real world industry are provided. The aspect of product life cycle on configuration management can be getting in [1]. Engineering knowledge management methodology related to product design (PLM) is given by Evans [2].

An interesting source of reference about configuration management is the defense industries. They use a number of standards that shaped the requirements for working according to configuration rules. In his book chapter 4, Lyon [3] describes key military standards in this industry with regard to configuration management.

Schur [4] claims that configuration refers to all the physical and functional features of the product, including hardware and software. This should be managed.

Configuration management according to principles Product Baseline Defined configuration of the product is determined in the first stages of the project [5].

A definition for Configuration changes is given by [4]. The research and development of a new product ends with the completion of the product design. However, in practice, changes in design that generate a configuration change may also be required at later stages, after production has begun.

Change management is one of the central, complexes and challenging processes in managing the project's configuration [6]. Managing changes and making changes in an engineering document is a direct result of the dynamism that accompanies the project. A change management process by ISO /IEC/IEEE 15288:2015 is given in Figure 1.

The main reference for configuration management is the CMII-version b [7]. The model provides a breakthrough for three management disciplines: Project Management, Configuration Management and Quality assurance.

According to the CMII model, the configuration managements discipline comprises from many elements, which can be found often under different names. The model brings Configuration Management elements under one umbrella and defines the overall 
effectiveness of the Configuration Management level of a specified organization by determine each elements and its own contribution to the overall CM level.

\begin{tabular}{|c|c|c|}
\hline $\begin{array}{c}\text { Design and } \\
\text { Development }\end{array}$ & Production & $\begin{array}{c}\text { Operations and } \\
\text { Support }\end{array}$ \\
\hline
\end{tabular}

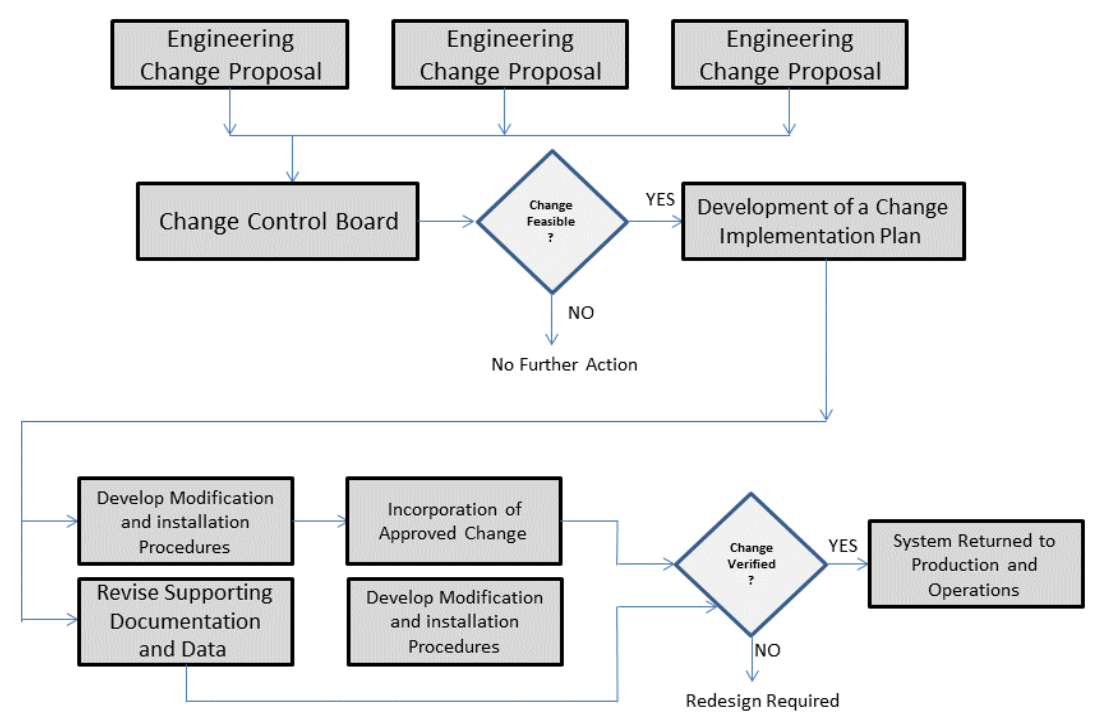

Fig. 1. Change Management Process according to ISO 15288.

The CMII determines that by improving information integrity, reducing the need for performing corrective actions and reducing re-work actions, the organization can focuses and invest its business and engineering resources to provide better business performance. It has seven explanatory variables with respect to configuration management: Requirements Management, Change Management, Release Management, Data Management, Records Management, Document Control and Library Management.

\subsection{Research objectives}

The purpose of the work is to obtain an up-to-date snapshot of the organization's perceived level of management by examining the level of implementation of the core areas of configuration management according to the model CMII (The model was chosen to serve as the basis for this study).

It is of interest to define the most perceived important factors that affect configuration management. The study aims to obtain a picture of the level of configuration management in hi tech industries as it perceived by professional and experienced system engineers and project managers in their own professional environment.

Two research hypotheses are defined.

H1 Do the factors in CMII affect configuration management and in what extent.

$\mathrm{H} 2$ The factors in CMII can be ordered in terms of significance and impact on configuration management. 


\section{Methodology}

The main mechanism of the study is a questionnaire based on the CMII framework. The questionnaire is spread among professionals in the area of system engineering. It is based on the protocol of CMII and contains 23 questions regarding to 23 statistical variables associated with the eight factors of CMII. Respondents also asked about their own opinions about practicing configuration management. There are questions about gender, education experience and task of respondents. The questionnaire was validated among expert judges, and some of the questions were re-formulated and some were rejected. The chosen scale of questions was the Likert scale without questions of the opposite meaning.

\subsection{The sample}

A comprehensive survey of potential respondents is conducted first in several hi-tech companies in Israel and 120 of them were found to be eligible for the study. They are experts and have been involved in configuration management and its application in their organizations. Out of 120 respondents 104 had answered the full questionnaire and were included in the study.

About $66 \%$ of the respondents have tasks in engineering departments. $36 \%$ of the respondents are engineers and $37 \%$ are managers. The empirical distribution of the respondents among disciplines is: mechanical engineering (10), system engineering (22), management (19), production integration (12), production engineering (10), software engineering (5) and services (3).

The Alpha Cronbach test for reliability is 0.895 which is well high and sufficient score. The 23 questions are associated with 23 statistical variables. The 23 statistical variables from the questionnaire are grouped into one dependent variable (GCM) and 7 independent variables in accordance with CMII as follow: (i) Requirements Management (REM), (ii) Change Management (CHM), (iii) Release Management (RLM), (iv) Data Management (DAM), (v) Report Management (RCM), (vi) Document Management (DOC), and (vii) Software Tools Management (SOT). Descriptive statistics about the Dependent variable $\mathrm{CM}$ and the seven explanatory variables are given in Table 1.

Table 1. Descriptive statistics of Configuration Management and seven explanatory variables.

\begin{tabular}{|l|c|c|c|}
\hline Name & Abbreviation & Mean & St. Dev. \\
\hline Configuration Management & GCM & 2.92 & 0.11 \\
\hline Requirements Management & REM & 3.97 & 0.09 \\
\hline Change Management & CHM & 3.92 & 0.09 \\
\hline Release Management & RLM & 3.94 & 0.09 \\
\hline Document Management & DAM & 3.06 & 0.12 \\
\hline Report Management & RCM & 3.92 & 0.08 \\
\hline Document Management & DOC & 4.03 & 0.09 \\
\hline Software Tools Management & SOT & 3.08 & 0.1 \\
\hline
\end{tabular}




\section{Results}

The first step of the statistical analysis is based on correlations between each of the seven explanatory variables with respect to configuration management (CM).

Table 2. Correlation coefficients of the seven explanatory variables and configuration management $\mathrm{CM}$.

\begin{tabular}{|r|c|c|c|c|c|c|c|c|}
\hline & GCM & REM & CHM & RLM & DAM & RCM & DOC & SOT \\
\hline GCM & 1 & & & & & & & \\
\hline REM & $0.592^{* *}$ & 1 & & & & & & \\
\hline CHM & $0.524^{* *}$ & $0.627^{* *}$ & 1 & & & & & \\
\hline RLM & $0.313^{* *}$ & $0.476^{* *}$ & $0.504^{* *}$ & 1 & & & & \\
\hline DAM & $0.695^{* *}$ & $0.568^{* *}$ & $0.499^{* *}$ & $0.369^{* *}$ & 1 & & & \\
\hline RCM & $0.569^{* *}$ & $0.596^{* *}$ & $0.599^{* *}$ & $0.448^{* *}$ & $0.553^{* *}$ & 1 & & \\
\hline DOC & $0.563^{* *}$ & $0.664^{* *}$ & $0.500^{* *}$ & $0.404^{* *}$ & $0.588^{* *}$ & $0.579^{* *}$ & 1 & \\
\hline SOT & $0.496^{* *}$ & $0.544^{* *}$ & $0.328^{* *}$ & $0.363^{* *}$ & $0.470^{* *}$ & $0.455^{* *}$ & $0.398^{* *}$ & 1 \\
\hline$* * \mathrm{p}<0.001, * * \mathrm{p}<0.01, * \mathrm{p}<0.05$ &
\end{tabular}

In Table 2 it seems that each one of the variables is significantly correlated positively with CM. The highest is 0.695.Data Analysis Management (DAM). The lowest is 0.313 Release Management (REM). It can be concluded that the hypothesis H1 is accepted.

A step-wise regression analysis is conduct to reveal that only three variables are found to be the most affecting CM. (Table 3).

Table 3. Regression of configuration management $\mathrm{CM}$ with the most contributing and significant factors out of the seven explanatory factors.

\begin{tabular}{|c|c|c|}
\hline Variable & Coefficient & p-value \\
\hline (Constant) & -.441 & .266 \\
\hline DAM & .439 & .000 \\
\hline REM & .278 & .016 \\
\hline RCM & .234 & .045 \\
\hline
\end{tabular}

The variables are DAM with an estimated marginal impact 0.439 . The other variable is REM with 0.278 , and the third and last variable is 0.234 . Other variables are not found to be contributed to the explanation of the variance of $\mathrm{CM}$. The results of the regression showed that there are groups of variables with a higher marginal effect, which leaves a higher overall significance. It can be concluded that while each variable contributes to the extent of CM' there are three factors that are more important than others. Their impact is also not equal.

After analyzing the results of the questionnaire and adjusting it to the rating scale in the model, a score was obtained indicating that the organization is at a level below the upper level of the configuration management (CMII). This means that the issue of configuration management has a significant emphasis on the organizations. At the same time, there are still issues that require improvement and changes. 


\section{Summary and conclusions}

The results of the study and work contributed greatly to understanding the importance of the organization's configuration management process. The characteristics and elements that comprise the content world of configuration management were presented; the strengths and weaknesses of the configuration management processes performed in the organizations included in this study. The results of the study are important and can give decision makers tools to improve processes and focus on issues that require improvement. The analysis of the open questions also contains a lot of valuable information that is recommended to be implemented in the near future: conducting process clarification, writing manuals, and more can be done immediately and raise the level of organizational management immediately and without significant costs.

The evaluation of the results of the study is that the decision makers in the organization should consider conducting a more in-depth examination based on a follow-up study of the organization's existing management system and examining the possibility of replacing it.

The configuration level can be further reviewed in another direction. For example, according to the life cycle of a project (development, production, maintenance, and dismantling - actually "focus" of configuration management on a specific cycle of life cycle), the questionnaire must be adapted to meet this requirement and perform an adjusted survey.

\section{References}

1. S. Globerson Shlomo, Operations Management and Performance Improvement (Deyonon, Tel Aviv University, 2002)

2. M. Evans, M. The PLM Debate: Outsourcing upsets the IT Integration Pillars in the Temple of Discrete Manufacturing (2001)

3. D. Lyon, Best Configuration Management Practices for the 21st Century (Raven Pub Co., 1999)

4. D. Shur, Quality Engineering (The Open University Press, Rannana, 1998)

5. P. Gandhi, IJERT, 2, 268 (2013)

6. J. Whyte, A. Statis, C. Lindkvist, IJPM, 34, 339-351 (2016)

7. Institute of Configuration Management CMII Model for Configuration Management Rev B (2003) 